\title{
Modelagem do fluxo sanguíneo através da malha adaptativa Autonomous Leaves Graph
}

\author{
Luiza Santana Pitangueira* Magno Tairone* \\ Departamento de Matemática, UFMG \\ 31270-901, Belo Horizonte, MG \\ E-mail: luiza.pitangueira@gmail.com, magnotairone@gmail.com, \\ Denise Burgarelli Duczmal \\ Universidade Federal de Minas Gerais- Departamento de Matemática \\ 31270-901, Belo Horizonte, MG \\ E-mail: burgarel@mat.ufmg.br.
}

\section{RESUMO}

Este trabalho trata de modelos matemáticos do escoamento sanguíneo baseados nas equações de Navier Stokes. A implementação utiliza a estrutura de malha adaptativa Autonomous Leaves Graph 2D (ALG) [1], desenvolvida em linguagem C++ com a biblioteca gráfica OpenGL.

Inicialmente estudamos e implementamos o escoamento de sangue em artérias, considerando um comportamento de fluido newtoniano, incompressível, com viscosidade constante em um escoamento uniforme. Este escoamento laminar determina um perfil parabólico, onde a velocidade é máxima no centro e nula junto às paredes. Nesta simulação usamos a estrutura ALG para o domínio computacional, discretizando o modelo matemático pelo método de volumes finitos. Em particular, utilizamos o método MAC (marker and cell [2]), para a discretização das equações diferenciais parciais.

Na segunda etapa deste trabalho estaremos estudando e implementando modelos com bifurcação [3] e aneurismas [4], refinando as regiões da malha onde o escoamento sofre mais variações. Neste caso, a viscosidade pode variar segundo diversos parâmetros, como por exemplo o diâmetro do vaso sanguíneo.

Os resultados serão comparados com os descritos nos artigos já publicados da área.

Palavras-chave: modelagem de fluidos, equações diferenciais parciais, métodos numéricos, malha adaptativa

\section{Referências}

[1] Burgarelli, D., Kischinhevsky, M., Biezuner, R. J.; A new adaptive mesh renement strategy for numerically solving evolutionary PDEs, Journal of Computational and Applied Mathematics, 196 (2006), 115-131.

[2] Fortuna, Armando de Oliveira; "Técnicas Computacionais para Dinâmica de Fluidos, Conceitos Básicos e Aplicações”, Edusp, 2000.

[3] Seo, T.; Numerical simulations of blood flow in arterial bifurcation models, Korea-Australia Rheology Journal, Volume 25 (August 2013),153-161, Issue 3,

[4] Weichert, F. et al.; Simulation of Intra-Aneurysmal Blood Flow by Different Numerical Methods, Computational and Mathematical Methods in Medicine, Volume 2013 (2013), 1-10, Article ID 527654. http://dx.doi.org/10.1155/2013/527654

*bolsista do Programa de Educação Tutorial Matemática 